Reprod. Nutr. Dévelop., 1988, 28 (6 A), 1531-1540

\title{
Inhibitory effect of homologous solubilized zona pellucida on rabbit in vitro fertilization
}

\author{
Martine DUMONT, Nicole CROZET
}

Station de Physiologie animale, I.N.R.A. 78350 Jouy-en-Josas, France

Summary. Rabbit zonae pellucidae were isolated using a modified technique of Dunbar et al. (1980). Zonae pellucidae were solubilized in saline phosphate buffer ( $\mathrm{pH} 7.8)$ for $30 \mathrm{~min}$ at $70^{\circ} \mathrm{C}$. One dimensional SDS-PAGE analysis showed that zona pellucida is essentially composed of three major proteins with apparent molecular weights of 200 $(275-165) \mathrm{kd}, 100(135-96) \mathrm{kd}$ and $75(96-51) \mathrm{kd}$.

Preincubation of sperm with heat-solubilized zonae pellucidae (SZP) (5 to $8 \mathrm{SZP} / \mu \mathrm{l})$ did not reduce sperm binding ability. By contrast, it significantly decreased the percentage of penetrated eggs (20 versus $73 \%$ for the control) and significantly reduced the fertilization rate (10 versus $55 \%$ for the control).

Ultrastructural analysis of several oocytes in the two groups demonstrated that inhibition of fertilization was not due to the inhibition of sperm-zona binding ability but essentially resulted from the impairment of sperm penetration through the zona pellucida.

\section{Introduction.}

In order to fertilize eggs, mammalian spermatozoa must firmly attach to the zona pellucida (ZP), an extracellular membrane which surrounds the oocyte. Two types of interaction between the sperm and the zona have been described (Hartmann et al., 1972 ; Bleil and Wassarman, 1983 ; Saling et al., 1979). Firstly, spermatozoa adhere loosely to the zona pellucida; this "attachment" is a reversible and unspecific adhesion. The second interaction or "binding " is a species-specific tighter adhesion which occurs only with capacitated spermatozoa. Several attempts have been made to identify and isolate the specific receptors involved in the process of sperm-zona binding in invertebrates as well as in mammals. Evidence shows that in mammals sperm-zona binding is mediated by a sperm receptor in the zona pellucida. In hamsters, cattle (Gwatkin and Williams, 1978) and mice (Bleil and Wassarman, 1980) pretreatment of capacitated spermatozoa with solubilized zonae pellucidae (SZP) reduces sperm binding ability and further penetration of the zona pellucida. In the mouse, one glycoprotein (ZP3, $83 \mathrm{kd}$ ) isolated from the zona is particularly involved in sperm-zona binding and induces the acrosome reaction of capacitated spermatozoa. 
The present study indicates that preincubation of in vivo-capacitated rabbit spermatozoa with heat-solubilized homologous zonae pellucidae inhibited their fertilizing ability. However, this effect apparently was not consecutive to the inhibition of sperm-zona binding capacity, but rather to the impairment of zona penetration by the bound sperm, thus differentiating sperm-zona binding from sperm penetration processes.

\section{Materials and methods.}

Oocyte and sperm collection. - Three-month old New-Zealand or Californian rabbit does were used. Ovulated eggs were collected from females superovulated with $2 \mathrm{mg}$ of FSH ( $\mathrm{p}$-FSH, Burns-Biotec) and $0.33 \mathrm{mg}$ of LH (Y. Combarnous, I.N.R.A. Nouzilly, France). The does were slaughtered $14 \mathrm{~h}$ post-coitum with a vasectomised buck, and the eggs were flushed from the oviducts with warm saline solution within 15 min after slaughter. The oocytes were rapidly denuded of the cumulus with hyaluronidase $(150 \mathrm{UI} / \mathrm{ml})$, and the corona cells were mechanically removed using small glass micropipettes. The oocytes were then rinsed three times in the fertilization medium (DM medium, Brackett and Oliphant, 1975).

In vivo capacited spermatozoa were collected by flushing each uterin horn 13 to $15 \mathrm{~h}$ post-coïtum with $2 \mathrm{ml}$ of B3 medium (Ménézo, I.N.R.A., France) or DM medium (Brackett and Oliphant, 1975).

Isolation of zonae pellucidae. - Zonae pellucidae were isolated using the procedure of Dunbar et al. (1980) with some modifications. Isolation of oocytes was carried out at $4{ }^{\circ} \mathrm{C}$. Ovaries collected within $15 \mathrm{~min}$ after slaughter of the does were placed in a $130 \mathrm{mM} \mathrm{NaCl}$ solution containing $10 \mathrm{mM}$ sodium phosphate, $1.5 \mathrm{mM}$ potassium phosphate, $2 \mathrm{mM}$ EGTA, $11 \mathrm{mM}$ sodium citrate, $25 \mathrm{mM}$ PVP 40 and $11 \mathrm{mM}$ benzamidin, at $\mathrm{pH} 7.0$. Ovarian follicles were ruptured with a vegetable-chopper. The released oocytes were washed through a series of nylon screens with meshes of $1600,217,153,106$ and $83 \mu \mathrm{m}$, respectively. The oocytes retained on the 106 and $83-\mu \mathrm{m}$ screens were separated from the remaining cells by centrifugation through a percoll gradient (at 5, 20 and $50 \%$ ).

Oocytes removed from the 0 to $20 \%$ fractions of the percoll gradient were gently homogenized in a potter in the same buffer. The zonae pellucidae were then collected on a 50- $\mu \mathrm{m}$ screen, washed three times with a phosphate saline solution $(\mathrm{pH} 7.8)$ and lyophilized or directly frozen in the buffer at $-20^{\circ} \mathrm{C}$. Some isolated zonae pellucidae were fixed for electron microscopy.

Solubilization and composition of the zona pellucida. - Zonae pellucidae were dissolved in saline phosphate buffer $\left(\mathrm{pH} \mathrm{7.8)}\right.$ at $70^{\circ} \mathrm{C}$ for $30 \mathrm{~min}$.

The protein composition of this solution was analysed by sodium dodecyl sulphate polyacrylamide gel electrophoresis according to the method of Laemmli (1970). We used a $2.5 \%$ acrylamide stacking gel and a separating gel which was a sigmoidal acrylamide gradient at 8 to $20 \%$ acrylamide concentration. Electro- 
phoresis was carried out at room temperature. The proteins migrated in the stacking gel for $20 \mathrm{~min}$ at a constant current of $20 \mathrm{~mA}$ per gel and in the separating gel for $5.5 \mathrm{~h}$ at a constant current of $30 \mathrm{~mA}$ per gel. The gels were stained using the silver staining method of Morrissey (1981).

In vitro fertilization. - Two hundred and fifty $\mu \mathrm{l}$ of in vivo-capacitated spermatozoa at a final concentration of $10^{5} \mathrm{spz} / \mathrm{ml}$ were incubated alone (control) or with solubilized zonae pellucidae (SZP) at a final concentration of 5 to $8 \mathrm{SZP} / \mu \mathrm{l}$ for 1 to $1.5 \mathrm{~h}$. Ovulated eggs were then added to the different samples of sperm. After $6 \mathrm{~h}$ of incubation at $38{ }^{\circ} \mathrm{C}$ under $5 \% \mathrm{CO}_{2}$, the eggs were examined for pronucleus formation and transferred to $400 \mu \mathrm{l}$ of B2 medium (Ménézo, I.N.R.A., France) containing $10 \%$ heat-inactivated rabbit serum. After $18 \mathrm{~h}$ of incubation, the eggs were examined under an inverted microscope for cleavage evaluation.

In vitro binding assay. - In this experiment, we used ovulated oocytes denuded of the cumulus and corona cells or follicular oocytes obtained during the isolation of the zonae pellucidae. These oocytes were able to bind spermatozoa in vitro (unpublished data).

Two hundred and fifty $\mu$ of in vivo-capacitated spermatozoa at a final concentration of $10^{5} \mathrm{spz} / \mathrm{ml}$ were incubated alone (control) or with solubilized zonae pellucidae at a final concentration of 5 to $5.5 \mathrm{SPZ} / \mu \mathrm{l}$ for 1 to $1.5 \mathrm{~h}$. Oocytes were then added and the gametes incubated for $1.5 \mathrm{~h}$ at $38{ }^{\circ} \mathrm{C}$ under $5 \% \mathrm{CO}_{2}$. At the end of the incubation period, the number of penetrated eggs ( $w$ ith at least one spermatozoon in the perivitelline space) was evaluated. The oocytes were washed several times by pipetting them with a small glass micropipette to remove loosely attached sperm at the zona surface. The number of spermatozoa tightly bound to the zona surface was evaluated under interference microscope.

Some of these oocytes were fixed for electron microscopy to assess more precisely the acrosomal status.

Electron microscopy. - Cytological procedures were as previously described (Crozet and Dumont, 1984).

\section{Results.}

Isolated zonae pellucidae. - Using the present procedure, an average number of $38 \pm 3 \mathrm{ZP}$ per ovary was recovered. Figure 1 shows whole rabbit zonae pellucidae after isolation as viewed with interference optics. To assess the purity of zona preparations, both electron microscopy and SDS-PAGE electrophoresis were used. At the ultrastructural level, only a very discrete contamination, probably originating from corona cell processes, was noticed on both the external and internal surfaces of the zonae (fig. 2). Monodimensional SDS-PAGE indicated that heat-solubilized zonae pellucidae were essentially composed of three major glycoproteins corresponding to apparent molecular weights of 200 

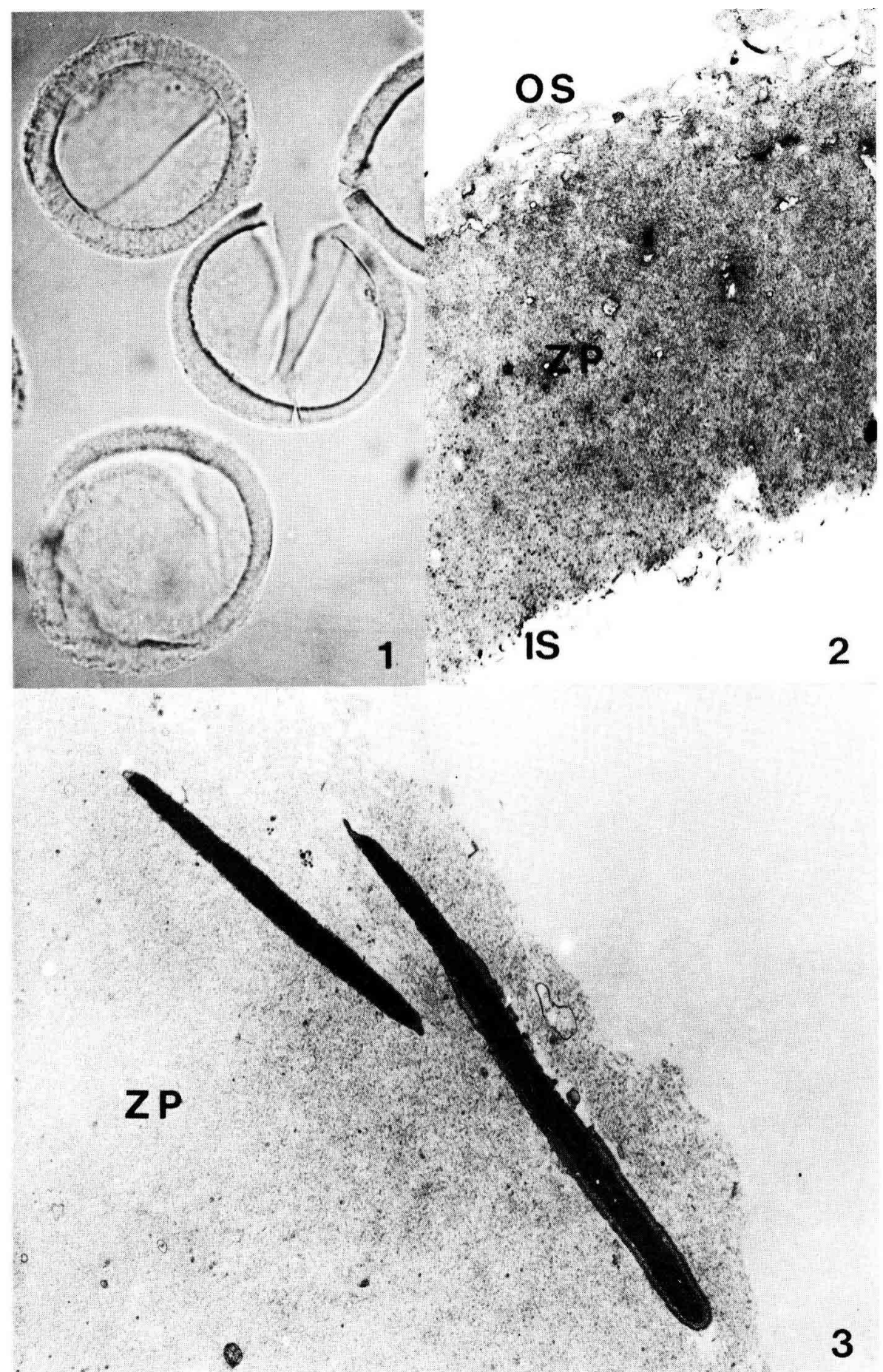
(270-165) kd, 100 (135-96) kd and 75 (96-51) kd respectively. These results are in agreement with those reported by Dunbar et al. (1981). Zonae were recovered from oocytes ranging between 75 to $125 \mu \mathrm{m}$ in diameter. In an attempt to assess whether the ZP of these oocytes was able to bind spermatozoa, oocytes of 75, 100 and $125 \mu \mathrm{m}$ in diameter were inseminated with in vivo-capacitated spermatozoa and processed for electron microscopy. All the oocytes were penetrated and acrosome-reacted spermatozoa were observed at their zona surface (data not shown).

In vitro fertilization by spermatozoa preincubated in the presence of heat SZP. - The results of in vitro fertilization are shown in table 1 . When spermatozoa were preincubated in the fertilization medium alone, $67 \%$ of oocytes were fertilized and underwent cleavage. By contrast, when spermatozoa were preincubated in the fertilization medium containing $5-8 \mathrm{SZP} / \mu \mathrm{l}$, only $10 \%$ of cleaved eggs was obtained. Therefore, the addition of SZP significantly reduced the rate of fertilization. The presence of the phosphate buffer in which the zonae pellucidae were solubilized cannot be taken into account because this addition to the preincubation medium did not significantly reduce the cleavage rate (55 versus $67 \% ; \mathrm{p}>0.05)$. Ova treated with SZP prior to the addition of capacitated spermatozoa were fertilized to the same extent as the control (table 2). The presence of SZP in the medium did not apparently decrease sperm motility. At the end of the incubation period (sperm preincubation and fertilization) 70 to $80 \%$ of highly motile spermatozoa were observed in the medium.

TABLE 1

Inhibition of in vitro fertilization by heat solubilized zonae pellucidae.

\begin{tabular}{|c|c|c|c|c|}
\hline & & Control No. 1 & Control No. 2 & $\begin{array}{l}\text { Experimental } \\
(5 \text { to } 8 \mathrm{SZP} / \mu \mathrm{l})\end{array}$ \\
\hline No. oocytes & (a) & 40 & 45 & 48 \\
\hline No. cleaving embryos & (b) & $27(67 \%)$ & $25(55 \%)$ & $5(10 \%)\left(^{*}\right)$ \\
\hline
\end{tabular}

(*) $\mathrm{P}<0.001\left(\chi^{2}\right.$ test $)$.

(a) Number of oocytes represent 4 experiments for control No. 1 and 5 experiments for control No. 2 and experimental; (b) Cleaving embryos obtained $24 \mathrm{~h}$ after insemination.

Control No. 1 : Spermatozoa were preincubated in the fertilization medium (DM medium).

Control No. 2 : Spermatozoa were preincubated in the fertilization medium containing $25 \%$ phosphate buffer.

Experimental : Spermatozoa were preincubated in the fertilization medium containing $25 \%$ phosphate buffer and solubilized zonae.

FIG. 1. - Rabbit zonae pellucidae isolated from follicular oocytes. $\times 240$.

FIG. 2. - Transmission electron micrograph of an isolated zona pellucida (ZP). Only very discrete contamination $(\rightarrow)$ were present on the inner surface (IS) and outer surface (OS) of the zona pellucida. $\times 6800$.

FIG. 3. - Two acrosome-reacted spermatozoa blocked in the outer part of the zona pellucida (ZP). Spermatozoa were preincubated with solubilized zonae pellucidae $(5-8 \mathrm{ZP} / \mu \mathrm{l}) . \times 35000$. 
TABLE 2

Fertilization rate of SZP pretreated rabbit oocytes.

\begin{tabular}{lcc}
\hline & Control & $\begin{array}{c}\text { Oocytes treated } \\
\text { with SZP }\end{array}$ \\
\cline { 2 - 3 } No. inseminated oocytes & 12 & 10 \\
No. penetrated oocytes & $10(83 \%)$ & $7(70 \%)$ \\
\hline
\end{tabular}

In another series of experiments, the ability of sperm preincubated in the presence of SZP, to bind to oocytes and penetrate the ZP was evaluated. The number of bound spermatozoa was identical both in the control and with SZP pretreated spermatozoa (table 3 ). However, preincubation of spermatozoa with SZP significantly reduced the number of penetrated eggs (20 versus $73 \%$ in the control) (table 3).

TABLE 3

Ability of SZP preincubated sperm to bind and to penetrate zona pellucida.

\begin{tabular}{|c|c|c|}
\hline & Control & $\begin{array}{c}\text { Experimental } \\
\text { (5 to } 5.5 \mathrm{SZP} / \mu \mathrm{l})\end{array}$ \\
\hline No. oocytes (a) & 45 & 44 \\
\hline No. sperm bound egg $\pm S D$ & $4.9 \pm 0.6$ & $4.5 \pm 0.5$ \\
\hline No. penetrated oocytes (b) & $33(73 \%)$ & $9(20 \%)\left(^{*}\right)$ \\
\hline
\end{tabular}

(') $P<0.005\left(\chi^{2}\right.$ test $)$

(a) Number of oocytes observed in 4 experiments; (b) Number of oocytes with at least one spermatozoon in the perivitelline space.

Control: Spermatozoa were preincubated in the fertilization medium with phosphate buffer.

Experimental: Spermatozoa were preincubated in the fertilization medium with phosphate buffer containing SZP.

Several oocytes from the two groups were analysed by electron microscopy (table 4$)$. In the control group $(n=9), 8$ spermatozoa (sectioned at the acrosome level) were observed at the zona surface : 6 were acrosome-reacted while 2 did not present any sign of acrosome reaction. Moreover, 16 spermatozoa were penetrating through the $\mathrm{ZP}$ and 5 were already in the perivitelline space. In oocytes inseminated with spermatozoa preincubated in the presence of SZP $(n=8), 12$ spermatozoa were observed at the zona surface : 8 acrosome-reacted and 4 with an intact acrosome. Eight spermatozoa were found in the outer part of the zona, but no further penetration was observed (fig. 3 ).

\section{Discussion.}

The present results clearly demonstrate that exposure of in vivo-capacitated rabbit spermatozoa to homologous heat-solubilized zonae pellucidae $(5-8 \mathrm{SZP} / \mu \mathrm{l})$ 
TABLE 4

In vitro interaction of rabbit sperm and zonae pellucidae. U/trastructural study.

\begin{tabular}{|c|c|c|c|c|c|c|c|}
\hline & & $\begin{array}{c}\text { No. } \\
\text { oocytes }\end{array}$ & $\begin{array}{l}\text { Al sperm } \\
\text { close to } \\
\text { the oocytes } \\
\text { (a) }\end{array}$ & $\begin{array}{l}\text { AR sperm } \\
\text { bound to } \\
\text { oocytes }\end{array}$ & $\begin{array}{l}\text { Al sperm } \\
\text { bound to } \\
\text { oocytes }\end{array}$ & $\begin{array}{l}\text { Sperm } \\
\text { in ZP }\end{array}$ & $\begin{array}{l}\text { Sperm } \\
\text { in PVS }\end{array}$ \\
\hline Control & & 9 & 1 & 6 & 2 & 16 & 5 \\
\hline Experimental & (b) & 8 & 1 & 8 & 4 & 8 & 0 \\
\hline
\end{tabular}

(a) Sperm close to the oocyte but not in contact with the zona pellucida; (b) Spermatozoa were pretreated with SZP ( 5 to $5.5 \mathrm{SZP} / \mu \mathrm{l}$ ).

AR : Acrosome-reacted; Al : Acrosome-intact; PVS: Perivitelline space.

significantly reduced their fertilizing ability. Similarly it was previously reported that SZP inhibited in vitro fertilization in hamster (Gwatkin and Williams, 1977 ; Ahuja and Tzartos, 1981). Exposure of spermatozoa to SZP had no detectable effect on their motility, but blocked their ability to fertilize eggs in vitro; therefore it may be assumed that the interaction of zona components with spermatozoa inhibits further zona binding and/or penetration. It was previously shown in mice (Bleil and Wassarman, 1980), hamster and cattle (Gwatkin and Williams, 1978) that SZP dramatically reduced the binding of capacitated spermatozoa to eggs. In the mouse, exposure to $\mathrm{O}$-linked oligosaccharides from ZP3, one of the 3 major glycoproteins of the ZP, prevented sperm binding to ovulated eggs (Florman and Wassarman, 1985). The present data, however, indicate that in the rabbit, a rather large number of SZP-treated spermatozoa were able to bind to the zona of oocytes and ovulated eggs. By contrast, the number of penetrated and fertilized eggs was lower than in control when the eggs were inseminated with sperm exposed to SZP. Therefore, in our conditions the interaction of SZP components with spermatozoa apparently blocked sperm-zona penetration rather than spermzona binding and acrosome reaction. Ultrastructural analysis of several eggs confirms these results. It indicates that exposure of spermatozoa to SZP prevented the sperm from penetrating further than the outer part of the zona pellucida. In no instance were such spermatozoa found in the perivitelline space, as was the case for untreated sperm. The number of sperm bound to the zona surface was not significantly different between the experiment and the control, and thus confirmed the evaluation at light microscopic level. However a higher number of spermatozoa inside the zona were observed by electron microscopy in the control than in eggs inseminated with SZP-preincubated sperm; therefore it appears that during the in vitro fertilization time lapse more spermatozoa effectively bound to eggs in the control than in experimental conditions; this indicated that exposure of sperm to SZP did not abolish their binding ability but partially decreased it.

In the rabbit, $\mathrm{O}^{\prime}$ Rand and coworkers isolated and characterized a sperm membrane autoantigen (RSA-1) which plays a role in sperm-zona penetration. This antigen was mainly localized over the postacrosomal region of the sperm head (O'Rand, 1981) ; antibody access was blocked when sperm were preincu- 
bated with SZP. The RSA-1 anti-serum highly decreased the ability of sperm to penetrate and fertilize the eggs although it did not inhibit sperm-zona binding. The author ( $O^{\prime}$ Rand, 1981) concluded that "penetration and binding are independent events which involve different but perhaps overlapping subsets of sperm surface components ". Our present results are in agreement with those reported by O'Rand. In the rabbit, however, it is difficult to explain why SZP did not inhibit sperm-zona binding as it did in hamster and cattle (Gwatkin and Williams, 1978) and mice (Bleil and Wassarman, 1980). It is possible that some alteration of the molecules involved in sperm-zona binding occurred during solubilization of the zonae pellucidae or that the factor was too much diluted ( 5 to $8 \mathrm{ZP} / \mu \mathrm{l})$ to be efficient.

One aim of our ultrastructural study was to assess the acrosomal status of spermatozoa bound to the zona pellucida. We found that both acrosome-intact and acrosome-reacted spermatozoa were able to bind to the zona pellucida; however most of them were acrosome-reacted in the control as well as in experimental conditions. These results may suggest that the acrosome reaction of untreated spermatozoa occurs at the zona surface as reported in other species (Saling and Storey, 1979; Bleil and Wassarman, 1983; Crozet and Dumont, 1984). They also suggest that when spermatozoa were preincubated with SZP, they underwent acrosome reaction in this medium as demonstrated in mice (Bleil and Wassarman, 1983), hamster (Cherr et al., 1986) and rabbit (O'Rand et al., 1987). According to Kuzan et al. (1984) acrosome-reacted spermatozoa were able to bind to the zona pellucida of eggs. Indeed acrosome-reacted spermatozoa released from the perivitelline space of fertilized eggs not only bind to the zona, but also repenetrate freshly ovulated eggs with a success rate of $24 \%$. Moreover, pretreatment of in vivo-capacitated rabbit spermatozoa with an antibody to the inner acrosomal membrane completely inhibits in vitro fertilization of rabbit ova (Srivastava et al., 1986). These data suggest that acrosome-reacted rabbit spermatozoa are able to bind to the zona pellucida. In the mouse several studies demonstrated that only acrosome-intact spermatozoa bind to the zona, while in the rabbit both acrosome-intact and acrosome-reacted sperm do this. In mice, two glycoproteins of the zona, ZP3 and ZP2, are involved in this process, but the mechanisms of sperm-zona binding in the rabbit remain to be clarified.

The site of the acrosome reaction of fertilizing sperm is not completely elucidated in this species. The results reported by O'Rand (1987) and the present data suggest that the acrosome reaction may occur at the zona surface. However, according to Kuzan et al. (1984) spermatozoa that have completed the acrosome reaction before reaching the zona surface do not lose their fertilizing ability. Some discrepancy exists between Kuzan's results and the present ones; indeed spermatozoa incubated with SZP that were presumably acrosome-reacted failed to give high rates of fertilization. Further experiments are needed to explain these contradictory observations and clearly demonstrate whether or not the acrosome reaction of the fertilizing sperm occurs at the zona surface in rabbit. 
Acknowledgments. - The authors are grateful to $\mathrm{C}$. Thibault for many valuable discussions and to J. L. Dacheux for help with electrophoretic analysis. They also thank E. Collas-Ouvrard and M. E. Marmillod for typing the manuscript and C. Slagmulder for the photographs.

Résumé. Inhibition de la fécondation in vitro chez le lapin par des zones pellucides homologues.

Des zones pellucides d'ovocytes folliculaires de lapines, isolées par la méthode de Dunbar et al. (1980), modifiée, sont dissoutes par la chaleur $\left(70^{\circ} \mathrm{C}\right.$ pendant $30 \mathrm{~min}$ ), dans un tampon phosphate. L'analyse de cette solution de protéines, par électrophorèse sur gel de polyacrylamide en présence de SDS, montre que la zone pellucide est essentiellement composée de 3 protéines majeures, de poids moléculaires apparents : $200(275-165) \mathrm{kd}$, $100(135-96) \mathrm{kd}$ et $75(96-51) \mathrm{kd}$.

La préincubation des spermatozoïdes avec des zones pellucides solubilisées ne diminue pas le nombre de spermatozoïdes fixés à la zone pellucide ; par contre, elle réduit significativement le pourcentage d'œufs pénétrés (20\% contre $73 \%$ pour le témoin) et le taux de fécondation ( $10 \%$ contre $55 \%$ pour le témoin).

L'étude ultrastructurale de plusieurs ovocytes dans les 2 lots montre que l'inhibition de la fécondation n'est pas essentiellement due à une diminution de l'attachement des spermatozoïdes à la zone pellucide, mais résulterait plutôt d'une inhibition de la pénétration des spermatozoïdes à travers celle-ci.

\section{References}

AHUJA K. K., TZARTOS S. J., 1981. Investigation of sperm receptors in the hamster zona pellucida by using univalent (Fab) antibodies to hamster ovary. J. Reprod. Fert., 61, 257-264.

BLEIL J. D., WASSARMAN P. M., 1980. Mammalian sperm-egg interaction; identification of a glycoprotein in mouse egg zonae pellucidae possessing receptor activity for sperm. Cell, 20, 873-882.

BLEIL J. D., WASSARMAN P. M., 1983. Sperm-egg interaction in the mouse. Sequence of events and induction of the acrosome reaction by a zona pellucida glycoprotein. Dev. Biol., 95, 317-324.

BLEIL J. D., WASSARMAN P. M., 1986. Autoradiographic visualisation of the mouse egg's sperm receptor bound to sperm. J. Cell Biol., 102, 1363-1371.

BRACKETT B. G., OLIPHANT G., 1975. Capacitation of rabbit spermatozoa in vitro. Biol. Reprod., 12, 260-274.

CHERR G. N., LAMBERT H., MEIZEL S., KATZ D. F., 1986. In vitro studies of the golden hamster sperm acrosome reaction. Completion on the zona pellucida and induction by homologous soluble zonae pellucidae. Dev. Biol., 114, 119-131.

CROZET N., DUMONT M., 1984. The site of the acrosome reaction during in vivo penetration of the sheep oocyte. Gamete Res., 10, 97-105.

DUNBAR B. S., LIU C., SAMMONS D. W., 1981. Identification of the three major proteins of porcine and rabbit zonae pellucidae by high resolution two dimensional gel electrophoresis : comparison with serum, follicular fluid and ovarian cell proteins. Biol. Reprod., 24, $1111-1124$.

DUNBAR B. S., WARDRIP N. J., HEDRICK J. L., 1980. Isolation, physicochemical properties, and macromolecular composition of zona pellucida from porcine oocytes. Biochemistry, 19. 356-365.

FLORMAN H. M., WASSARMAN P. M., 1985. O-Linked oligosaccharides of mouse egg ZP3 account for its sperm receptor activity. Cell, 41, 313-324. 
GWATKIN R. B. L., WILLIAMS D. T., 1977. Receptor activity of the hamster and mouse solubilized zona pellucida before and after the zona reaction. J. Reprod. Fert., 49, 55-69.

GWATKIN R. B. L., WILLIAMS D. T., 1978. Bovine and hamster zona solution exhibit receptor activity for capacitated but not for non capacitated sperm. Gamete Res., 1, 259-263.

HARTMANN J. F., GWATKIN R. B. L., HUTCHINSON C. F., 1972. Early contact interactions between mammalian gametes in vitro: evidence that the vitellus influences adherence between sperm and zona pellucida. Proc. nat. Acad. Sci. USA, 69, 2767.

KUZAN F. B., FLEMING A. D., SEIDEL G. E., 1984. Successful fertilization in vitro of fresh intact oocytes by perivitelline (acrosome-reacted) spermatozoa in the rabbit. Fertil. Steril., 41. 766-770.

LAEMMLI U. K., 1970. Cleavage of structural proteins during the assembly of the head of bacteriophage T4. Nature, 227, 680-685.

MORRISSEY J. H., 1981. Silver stain for proteins in polyacrylamide gels. A modified procedure with enhanced uniform sensitivity. Anal. Biochem., 117, 307-310.

O'RAND M. G., 1981. Inhibition of fertility and sperm zona binding by antiserum to the rabbit sperm membrane autoantigen RSA-1. Biol. Reprod., 25, 621-628.

O'RAND M. G., FISHER S. J., 1987. Localization of zona pellucida binding sites on rabbit spermatozoa and induction of the acrosome reaction by solubilized zonae. Dev. Biol., 119 , $551-559$.

SALING P. M., SOWINSKI J., STOREY B. T., 1979. An ultrastructural study of epididymal mouse spermatozoa binding to zonae pellucidae in vitro: sequential relationship to the acrosome reaction. J. exp. Zool., 209, 229-238.

SALING P. M., STOREY B. T., 1979. Mouse gamete interactions during fertilization in vitro. Chlortetracycline as a fluorescent probe for the mouse acrosome reaction. J. Cel/ Biol., 83 , 544-555.

SRIVASTAVA P. N., SHEIKHNEJAD R. G., FAYRER-HOSKEN R., MALTER H., BRACKETT B. G., 1986. Inhibition of fertilization of rabbit ova, in vitro, by the antibody to the inner acrosomal membrane of rabbit spermatozoa. J. exp. Zool., 238, 99-102. 